\title{
LA IDENTIDAD Y EL COMPORTAMIENTO DEL MAÍZ BT El debate sobre la predicción de las posibles consecuencias adversas de la ingeniería genética
}

\author{
IDENTITY AND BEHAVIOUR OF BT CORN
}

The debate about the prediction of the potentially adverse consequences of the genetic engineering

\author{
JóseAn LARRIÓN CARTUJO \\ Universidad Pública de Navarra. España. \\ josean.larrion@unavarra.es
}

\begin{abstract}
RESUMEN
Este trabajo analiza las principales causas y consecuencias relacionadas con el poderoso entramado científico y tecnológico propio de las sociedades occidentales contemporáneas. Más concretamente, se examina la polémica singular sobre la creación, el cultivo y el comercio de un tipo de maíz transgénico propiedad de la empresa multinacional Syngenta. En contra de las concepciones del quehacer investigador más idealistas y metafísicas, se sostiene que el desarrollo de las investigaciones puede no garantizar necesariamente la clausura futura de determinadas discusiones asociadas al actual complejo científico y tecnológico. Con arreglo a una perspectiva analítica de la nueva tecnociencia más crítica y reflexiva, por tanto, se exploran las heterogéneas traducciones colectivas aqui activadas y movilizadas y se investiga qué grupos sociales específicos salen más o menos beneficiados o perjudicados de la libre proliferación mundial de estos organismos modificados genéticamente.
\end{abstract}

\section{Palabras Clave}

Controversias, Expertos, Incertidumbre, Seguridad, Tecnociencia.

\section{Abstract}

The current article analyses the main causes and consequences related to the powerful scientific and technological network of the contemporary occidental societies. Specifically, it is examined the particular controversy about the creation, growing and commercialization of a transgenic corn variety which it is property of a multinational enterprise called Syngenta. In opposition to the more idealistic and metaphysical perspectives of the research practice, in this work it is proposed that the development of the research may not completely guarantee the future closure of some problems related with the present scientific and technological system. Bearing in mind a more critical and reflexive point of view about the new technoscience, it is explored the dissimilar collective translations activated and mobilized here and it is investigated which particular social groups are benefited and which others are harmed by the conflict of the free global propagation of these genetically modified organisms.

\section{KEYWORDS}

Controversies, Experts, Safety, Technoscience, Uncertainty. 


\section{INTRODUCCIÓN}

En este trabajo procedo en un sentido amplio al estudio social de las principales causas y consecuencias relacionadas con el poderoso entramado científico y tecnológico propio de las actuales sociedades occidentales. Desde el punto de vista de las nuevas orientaciones en la Sociología de la Ciencia y la Tecnología, investigo la controversia general desatada en torno a la libre proliferación mundial de los alimentos modificados genéticamente. Más concretamente, describo y analizo la polémica particular erigida en relación con la creación, el cultivo y el comercio del denominado maíz Bt, o maíz Bacillus thuringiensis, que es un tipo de maíz transgénico propiedad de la empresa multinacional Syngenta. De la mano de este objeto empírico de estudio y claramente en contra de las habituales concepciones del quehacer investigador más idealistas y metafísicas, busco documentar que el relativo desarrollo de las investigaciones, lo que se interpreta con mucha frecuencia como más rigurosidad, más solvencia y más objetividad, puede no garantizar necesariamente la clausura futura de determinadas discusiones asociadas al actual complejo científico y tecnológico. En último término, procuro evidenciar cómo los colectivos sociales partidarios de la nueva ingeniería genética forcejean de continuo mediante la articulación de variadas estrategias con el fin esencial de persuadir a las sociedades en general de que el conjunto de los contra-argumentos presentados por los colectivos sociales detractores de este producto transgénico específico no merece ser considerado, de acuerdo sobre todo con el así llamado principio de precaución, como una duda científica realmente razonable y significativa que justifique una actitud social generalizada de alarma, sospecha y preocupación (Sentís Castaño, 2002; Ramos Torre, 2002).

Claro que para afrontar estos objetivos, según han advertido también ciertos expertos aquí involucrados, nunca debería olvidarse una cuestión innegablemente clave y fundamental. Me refiero muy en particular al siguiente interrogante: «¿Aquién le interesa que se cultiven plantas modificadas genéticamente?» (Chapela, 2005: 36). Con arreglo pues a una perspectiva analítica de la nueva tecnociencia mucho más crítica y reflexiva, se exploran las heterogéneas traducciones colectivas aquí activadas y movilizadas y se persigue comprender y explicar qué grupos sociales específicos salen más o menos beneficiados o perjudicados de la libre proliferación mundial de estos organismos modificados genéticamente (OMG). Con estas exigentes intenciones de fondo, por tanto, el presente trabajo se centra también en analizar cuestiones más puntuales y específicas relacionadas con la discutida existencia de la incertidumbre científica, el problema del reconocimiento de una duda científica razonable, la cuestionada validez ecológica de los experimentos cientíicos y el siempre forzado, violento y arriesgado paso de los laboratorios a la naturaleza exterior. Y el motivo primordial que nos impulsa a ahondar en el conocimiento de estas realidades humanas en apariencia tan sencillas, evidentes y aproblemáticas consiste precisamente en que justo desde ahí se puede forjar una idea mucho más precisa y rigurosa tanto sobre la irreductible condición social de la racionalidad y la experimentación como sobre la muy ardua y peliaguda predicción de los 
posibles efectos futuros asociados a los productos y las prácticas de la nueva ingeniería genética (Bourdieu, 2003; Mendiola, 2006).

\section{EL LeNGUAJE de LAS CERTIDUMBRES}

Inicialmente, merece recordarse que la abreviatura específica en cuestión remite a una bacteria que los expertos aquí implicados denominan formalmente como Bacillus thuringiensis (Bt). En términos oficiales, los cultivos Bt son un tipo de plantas modificadas genéticamente para ser resistentes a determinados insectos que se consideran dañinos para los intereses de los distintos agricultores. Más en particular, estos nuevos productos serían eficientes sólo en la medida en que las esporas producidas por esta bacteria contienen una toxina (Cry $1 \mathrm{Ab}$ ) que se activa por la acción enzimática que tiene lugar en el aparato digestivo de los insectos con digestión alcalina. Su ingesta provocaría al parecer que estos insectos dañinos dejaran de alimentarse y murieran en muy pocos días. Asimismo, debe indicarse que este tipo de plantas se produce y consume en variedades como el algodón, la patata y el maíz desde el año 1996 en EEUU En otros países como Argentina o Canadá, el cultivo del maíz transgénico comenzó ya en el año 1997. Con todo, tanto el cultivo como el consumo de este tipo de maíz habrían sido autorizados sólo en un único país de la UE. Según es sabido, este país sería España y la autorización inicial respectiva tendría lugar en el mes de marzo de 1998 (BOE, 26 de marzo de 1998). Entre las variedades cultivadas en los campos españoles se encuentran el maíz Compa CB y el maíz Jordi CB, ambas propiedad de la empresa multinacional Syngenta. En lo que respecta a las cantidades cultivadas, resaltando que estas cifras no son muy transparentes ni fácilmente contrastables, cabe indicar que en los campos españoles se habrían cultivado en torno a 20.000 hectáreas de maíz transgénico Bt en el año 2002, 32.000 en 2003, 58.000 en 2004 y hasta 70.000 en 2005. No obstante, debido al padecimiento de una grave sequía, sólo se cosecharon en el país unas 48.000 hectáreas de maíz durante 2005. El total de hectáreas de maíz transgénico alcanzó sin embargo el $11 \%$ del total del maíz cultivado en España. Así lo indican cuando menos los datos que difunde el International Service for the Acquisition of Agri-Biotech Applications (ISAAA) (James, 2005).

Igualmente, cabe apuntar que el maíz transgénico Bt es un producto diseñado y desarrollado en un laboratorio situado en el Research Triangle Park de Carolina del Norte, en EEUU. El grupo de trabajo fue liderado por el científico K. Koziel, mientras que la mayor parte de la financiación económica corrió a cargo de la empresa suiza Ciba Seeds. No obstante, dicha empresa fue conocida con posterioridad como Novartis y en la actualidad se denomina Syngenta tras su fusión con la compañía AstraZeneca. En lo que ahora sigue, por consiguiente, expondré y analizaré, sobre todo, los argumentos y las pruebas empíricas esgrimidos por los grupos sociales partidarios de la libre proliferación mundial de estos OMG. 
El objetivo oficial del maíz Bt sería acabar con el conjunto de los importantes daños y perjuicios, desde el punto de vista de la rentabilidad económica que buscan los distintos colectivos aquí involucrados, que un insecto específico conocido como el taladro ocasionaría a los diversos cultivos de maíz. En particular, expresiones tales como piral, taladro, barrenador o gusano cogollero serían algunos de los nombres más comunes de Ostrinia Nubilalis, Sesamia Nonagroides o Diatraea Grandiosella. Son éstos, pues insectos lepidópteros depredadores del maíz que representarían, en principio, una de las plagas más importantes que los cultivos de maíz han sufrido y siguen sufriendo en gran parte del mundo. Dichos insectos son en buena medida conocidos desde principios del siglo XX. Y en la actualidad se encuentran extendidos también por toda la Península Ibérica, las Islas Baleares e incluso las Islas Canarias. Las provincias españolas donde el taladro generaría mayores destrozos y donde se habría cultivado el maíz transgénico en cuestión son sobre todo Gerona, Huesca, Lérida, Navarra y Zaragoza.

En general, los programas convencionales no-transgénicos destinados al control de los insectos dañinos se basan de manera casi exclusiva en la aplicación de insecticidas químicos (lannone, 2001). Estos insecticidas tradicionales se aplicarían o bien mediante su disolución en el agua de riego o bien a través de su pulverización aérea realizada con la ayuda de avionetas. En particular, las posiciones a favor de la utilización del maíz Bt consideran que la lucha tradicional mediante productos químicos no sería realmente eficaz debido sobre todo a una peculiaridad del comportamiento de estos insectos. Así, resulta que el insecticida convencional sería un insecticida químico ideal si no fuera por la dificultad que conlleva su correcta aplicación. De hecho, se sostiene que los programas tradicionales no serían eficaces contra los taladros del maíz debido a que estos insectos se encontrarían protegidos en el interior de las plantas frente a la acción de las partículas pulverizadas. Además, las plagas se desarrollan de una manera tan sutil y devastadora que cuando el agricultor se percata del problema por regla general ya suele ser demasiado tarde. En consecuencia, pese al empleo masivo de tales sustancias químicas, la industria del sector agroalimentario insiste en afirmar que se seguirían perdiendo del $10 \%$ al $30 \%$ de las cosechas mundiales debido a la acción de estos insectos perjudiciales. Asimismo, un problema añadido sería que estos insecticidas se compondrían en la mayor parte de los casos de productos químicos altamente tóxicos para un amplio espectro de organismos. De ahí que el desarrollo de un maíz transgénico resistente a la oruga del taladro, sostienen los grupos sociales partidarios del maíz Bt, pudiera constituir una excelente alternativa frente a las estrategias químicas tradicionales (Martínez, 1997).

Y así cabe interpretar que una de las metas esenciales sería convertir el campo y la naturaleza en un bello y rentable jardín, es decir, en un espacio acotado siempre seguro, limpio y controlado (Mendiola, 2006). En coherencia, se entiende que los colectivos sociales partidarios de estos productos procuren convencer a los agricultores de los grandes beneficios económicos y ambientales que les podría generar el cultivo del maíz Bt. Sobre los supuestos beneficios monetarios que el maíz transgénico ya habría generado por ejemplo a los distintos agricultores del noreste español, de hecho, es famoso el Informe favorable realizado durante el periodo comprendido entre 1998 y 2002 por el 
experto en economía Graham Brookes a petición de la asociación europea de empresas dedicadas a la biotecnología y conocida como EuropaBio (Mármol, 2002). Con todo, una de las estrategias principales que las grandes empresas del sector agroalimentario emplean para persuadir a la sociedad en general consiste en reiterar de continuo que los alimentos transgénicos podrían representar una herramienta muy eficaz y poderosa en la necesaria lucha contra el hambre en el mundo (Alcalde, 1997). Por ello, se mantiene que oponerse al libre cultivo y comercio internacional de los productos transgénicos equivaldría en la práctica a retrasar la necesaria solución a estos graves problemas que afectan por desgracia a una gran parte de la humanidad. Se concluye por tanto que renunciar a los alimentos transgénicos sería poco menos que dar la espalda a los muy relevantes y esperanzadores logros actuales de la ciencia y la tecnología (Borlaug, 1999).

Asimismo, uno de los trabajos científicos que suele prestar más razones y argumentos a los grupos sociales partidarios del maíz Bt es el estudio realizado en el año 1998 por los investigadores Brake y Vlachos (Brake y Vlachos, 1998). En concreto, este trabajo empírico se centró en examinar el maíz Bt de la empresa Novartis (Evento 176). El experimento en cuestión se realizó con pollos y tuvo una duración de 38 días. De estos pollos, unos fueron alimentados con el citado maíz transgénico mientras que los otros pollos, los animales pertenecientes al grupo de control, fueron alimentados con un tipo de maíz convencional no-transgénico. El citado trabajo concluyó, por un lado, señalando la ausencia de diferencias estadísticas notorias en los índices de supervivencia de los pollos y, por otro lado, indicando incluso un incremento significativo de los pesos genéricos y específicos relativos a las diferentes partes del cuerpo de los respectivos animales.

Igualmente, para defenderse de ciertas acusaciones, los grupos partidarios de la nueva ingeniería genética alegan que en muchas ocasiones se omitiría decir que los insecticidas químicos que se usan con mucha frecuencia en el cultivo del maíz no transgénico serían tan nocivos para algunos insectos no dañinos como los producidos supuestamente por el polen de las plantas transgénicas. Así, se denuncia que los principales grupos ecologistas estarían omitiendo por ejemplo que los insecticidas químicos que se usan por lo general en el cultivo del maíz convencional serían tanto o más perniciosos para ciertos insectos no perjudiciales que el polen de las plantas modificadas genéticamente. Por consiguiente, se utiliza como contra-argumento que la exposición de ciertas especies de insectos no dañinos a la toxina transgénica no sería tan elevada, intensa y negativa para estos insectos como la propia exposición derivada del uso químico tradicional de la toxina Bt (Peinado, 1999: 44).

Muy en particular, las críticas centrales de los colectivos partidarios de estos nuevos productos se dirigen por ejemplo contra la muy conocida y polémica investigación realizada y publicada por el grupo de trabajo de John E. Losey (Losey, et al. 1999). La finalidad principal de este trabajo, que luego expondré con más detenimiento, consistió en examinar los posibles daños que el polen transgénico liberado al medio ambiente podría generar sobre las larvas de las mariposas Monarca. En concreto, cabe apuntar que éstas son unas mariposas de color negro, blanco y naranja, tienen una alta capacidad migratoria y son conocidas también como Dannaus Plexipus. Los grupos partidarios 
del maíz Bt denuncian así que dicho trabajo sería en realidad un singular estudio de laboratorio llevado a cabo en condiciones muy forzadas y artificiales de alimentación de las orugas de la mariposa Monarca. Se sugiere además que este grupo de especialistas podría estar vinculado de una manera muy estrecha y sospechosa a algunos de los actuales movimientos ecologistas, naturalistas o ambientalistas. Lo cual, al parecer, podría poner en entredicho la solvencia y la objetividad que se les presuponen a estas personas en tanto que expertos plenamente neutrales, imparciales e independientes (Muñoz Ruiz, 2002: 15-17).

Justamente, serían muchas las críticas dirigidas a la investigación realizada y publicada por el grupo de Losey (Silva Castro, 2005: 44-46). Así, según habría indicado por ejemplo Francisco García Olmedo, catedrático de bioquímica y biología molecular en la Universidad Politécnica de Madrid, si bien sería posible que muchas de las mariposas que fueron forzadas a alimentarse del maíz transgénico murieran o sufrieran daños muy graves, de igual modo debe explicitarse que si estas mismas mariposas hubieran sido forzadas a alimentarse de un maíz convencional tratado con los insecticidas químicos no transgénicos éstas podrían haber padecido daños similares o incluso más perjudiciales (Peinado, 1999: 44). En consecuencia, muchos de los científicos y técnicos expertos partidarios de estos nuevos productos coinciden en denunciar que los resultados empíricos obtenidos en este experimento concreto no serían en modo alguno extrapolables a lo que realmente podría llegar a ocurrir en el campo abierto (Sampedro, 1999).

Con parecida motivación, también en respuesta más o menos directa al citado trabajo del grupo de John Losey, merece indicarse que el 16 de octubre del año 2000 fue emitido un Informe de la Environmental Protection Agency (Agencia de Protección Ambiental de EEUU) (EPA). Este estudio fue realizado y presentado a través de su respectivo grupo científico asesor conocido como Scientific Advisory Panel (SAP) (EPA, 2000). En este trabajo participaron en torno a 20 entomólogos de 10 Universidades de Canadá y EEUU. Y en dicho documento se alcanzaron al parecer las siguientes conclusiones fundamentales (Sears et al. 2001). En primer lugar, en relación con el estudio del posible impacto negativo sobre la salud humana del maíz Bt, se afirmó que no existirían evidencias científicas que confirmen que las toxinas transgénicas causen ningún tipo de reacciones alérgicas y perjudiciales. En segundo lugar, respecto a la respectiva evaluación ambiental, se sostuvo que tampoco se habría registrado ningún tipo de problemas ni en relación con la posible hibridación cruzada de las plantas Bt con otras plantas locales ni en relación con la posible incidencia negativa sobre los animales beneficiosos, los organismos de los suelos o el conjunto de la vida silvestre. En tercer lugar, el Informe señaló dos beneficios esenciales asociados al cultivo del maíz Bt. Por un lado, las ganancias económicas directas que el maíz transgénico generaría a los agricultores y los empresarios y, por otro lado, los beneficios ambientales indirectos que este tipo de maíz produciría con la reducción de en torno a un tercio en el uso de los insecticidas químicos convencionales. El citado Informe, en cuarto lugar, concluyó que, en lo tocante al posible problema de la aparición de hipotéticas resistencias en los insectos perjudiciales, el actual régimen de gestión de las resistencias sería el correcto y adecuado. 
En todo caso, en una sección dedicada al análisis de los posibles impactos negativos sobre las referidas mariposas ocasionados por las plantas transgénicas Bt, el Informe manifestó que, de acuerdo con las evidencias científicas actualmente disponibles y reconocibles, existiría una probabilidad muy baja de generar unos efectos adversos para la salud de las mariposas Monarca. El documento conjunto de la agencia norteamericana, por tanto, finalizó resaltando que la información científica preliminar publicada sobre la hipotética toxicidad de estos productos no sería realmente suficiente y significativa como para justificar una preocupación social fundada en relación con la posible incidencia negativa de las proteínas transgénicas sobre las mencionadas mariposas Monarca (EPA, 2000).

A modo de resumen, por ende, quienes apuestan por estos nuevos productos y prácticas afirman que sólo mediante la superación de todos estos miedos, temores y prejuicios científicamente injustificados la sociedad actual podrá aspirar a convertirse en una sociedad realmente próspera, avanzada y desarrollada. Así, según ha concluido por ejemplo un conocido ingeniero agrónomo español que trabaja para la empresa multinacional Novartis Seeds: "El campo necesita soluciones, seguramente la biotecnología no es la única, pero abre muchas alternativas. Renunciar a la ciencia, a la innovación y al progreso no es el mejor camino. Démosle una oportunidad, con todos los controles del mundo, pero basados en la razón, no en el miedo infundado» (Alcalde, 2000: 49).

Es obvio que hasta aquí el lenguaje social que subraya las seguridades y las certidumbres ganaría claramente la batalla discursiva a ese otro lenguaje social que resalta los riesgos y las incertidumbres. No obstante, resulta también evidente que de momento sólo he presentado con cierto detalle una de las dos partes principales enfrentadas en esta singular polémica, en gran medida narrativa y simbólica, consistente en establecer públicamente quién conoce realmente y con más profundidad la identidad, el comportamiento presente y las hipotéticas consecuencias futuras relacionadas con estos OMG (Syngenta Seeds, 1997). Sea como fuere, según en ocasiones parecen haber asumido igualmente ciertos actores sociales aquí involucrados, queda claro que los diferentes colectivos humanos interactúan y forcejean así para apropiarse del monopolio de las representaciones científicas y técnicas legítimas de los posibles efectos adversos asociados al comentado maíz Bt. Así las cosas, la mirada sociológica más crítica y reflexiva encuentra en este singular debate actual una muy buena ocasión para subrayar la naturaleza fragmentaria, provisional y controvertida de toda forma de conocimiento y representación (Beltrán Villalva, 2000; Bourdieu, 2003).

\section{EL LENGUAJE DE LAS INCERTIDUMBRES}

En contraposición, como es de esperar, los grupos sociales detractores del maíz transgénico se sirven de argumentos y pruebas empíricas muy diferentes a los movilizados por los grupos sociales partidarios de la nueva ingeniería genética (Spendeler y 
Carrasco, 2003). Por ejemplo, según ya adelanté, estos colectivos críticos sostienen que rigurosos estudios científicos habrían demostrado que el maíz Bt podría generar unos efectos realmente negativos sobre algunos insectos beneficiosos tales como las mariposas Monarca. Se alude aquí muy en especial a los estudios de campo publicados en la prestigiosa revista británica Nature y realizados por el grupo de trabajo liderado por John E. Losey, un profesor de entomología de la Universidad de Cornell, Ithaca, Nueva York (Losey, et al. 1999). Justamente, según respaldaron después por ejemplo otros investigadores de la Universidad del Estado de lowa, se subraya así que este estudio sería una de las investigaciones más importantes que habría explicitado que el maíz transgénico que genera la toxina Bt poseería un efecto realmente grave sobre las larvas de las mariposas Monarca (Hanson-Jesse y Obrycki, 2000; Obrycki, et al. 2001).

Así, el referido fenómeno en campo abierto ocurriría de la manera siguiente. En un principio, el polen del maíz transgénico que genera la toxina Bt sería dispersado por la acción del viento y depositado sobre otras plantas como la lechetrezna que crece junto a los campos de maíz y que constituye el alimento principal de las larvas de estas mariposas. Por ende, los investigadores del grupo de Losey habrían alimentado en el interior del laboratorio a las larvas de estas mariposas con unas hojas de lechetrezna impregnadas con el polen del maíz Bt. En consecuencia, el resultado más importante de este experimento habría indicado un claro envenenamiento de estas larvas. Más en concreto, se sostuvo que las larvas que se alimentaron con las hojas de lechetrezna espolvoreadas con el polen del maíz Bt comían menos, crecían de una manera más lenta y tenían una mayor tasa de mortalidad que las larvas del grupo de control que fueron alimentadas con lechetrezna espolvoreada con el polen del maíz convencional. Así, como por ejemplo ha expresado la doctora Linda S. Rayor, quien fuera coautora de esta misma investigación: "Lo que es nuevo en este estudio es que hemos demostrado que las toxinas pueden flotar en el viento" (Arias, 2000). De hecho, se indicó que en sólo 48 horas habrían muerto hasta el $50 \%$ de los ejemplares, mientras que habrían sobrevivido la totalidad de los insectos que conformaban el grupo de control. Por consiguiente, según se recoge en la referida publicación, los resultados empíricos habrían mostrado que murieron más de la mitad de las orugas que comieron las hojas de lechetrezna espolvoreadas con el polen del maíz Bt. El conflicto entre la citada mariposa y el maíz Bt, sumándose al problema cardinal que ya padecerían estos insectos en relación con la necesaria conservación de su frágil hábitat natural, se habría convertido así para los grupos sociales más críticos en un símbolo dramático de los riesgos adversos asociados a las nuevas biotecnologías de la agricultura y la alimentación (Pacheco-Vega y Vega-López, 2001).

Análogamente, los grupos sociales detractores del maíz Bt han denunciado que fenómenos semejantes a los detectados por el grupo de John Losey habrían sido identificados ya respecto a la difícil convivencia entre el maíz transgénico e insectos no dañinos como las mariquitas. En este contexto, se recuerdan los resultados empíricos de un estudio de laboratorio realizado en Suiza por los científicos Hilbeck, Baumgartnew, Fried y Bigler (Hilbeck, et al. 1998). Según se muestra en este estudio, por ejemplo, cuando las mariquitas se alimentan del barrenador europeo del maíz Bt, éstas sufrirían 
una alteración significativa de su desarrollo normal y un incremento preocupante de sus índices de mortalidad. Otro experimento de laboratorio llevado a cabo en el Instituto de Investigaciones de Cultivos de Escocia concluyó que, de forma similar, las patatas modificadas genéticamente para ser resistentes a las plagas de insectos también podrían dañar a algunos insectos beneficiosos en los eslabones superiores de la cadena alimentaria (Birch, et al. 1996-1997). En este otro caso, se alimentaron mariquitas hembra con áfidos que habían sido alimentados a su vez con patatas modificadas genéticamente. De hecho, cuando se compararon estos insectos con los animales del grupo de control, se observó que las mariquitas hembra ponían menos huevos y vivían en torno a la mitad de lo esperado.

Asimismo, otro estudio del que se sirven con gran frecuencia y entusiasmo los colectivos sociales detractores del maíz transgénico para fortalecer sus razones y argumentos y para, de manera inversa, debilitar las razones y los argumentos de los colectivos sociales partidarios de la libre circulación de estos nuevos productos es el conocido y polémico trabajo realizado por los científicos Ignacio H. Chapela y David Quist (Quist y Chapela, 2001). Se trata, no obstante, de un estudio cuyos resultados preliminares fueron adelantados dos meses antes en el mismo medio de comunicación (Dalton, 2001). La investigación en cuestión, publicada el 29 de noviembre de 2001 en la revista Nature, fue presentada pues por Ignacio $\mathrm{H}$. Chapela, un profesor de micología y microbiología del Departamento de Ciencias Ambientales de la Universidad de Berkeley, en California, en colaboración con David Quist, quien fuera por entonces estudiante en esta misma Universidad. Este trabajo, al parecer, presentaba evidencias científicas de que genes procedentes de un maíz modificado genéticamente se habrían cruzado con maíz autóctono de algunas zonas del sur de México. Según dicho estudio, por tanto, los nuevos genes se habrían establecido de un modo claramente estable y permanente en el genoma de las especies autóctonas, proceso éste que los expertos respectivos denominan con frecuencia como introgresión. Más en concreto, se sostuvo que en septiembre de 2001 se habrían encontrado evidencias empíricas de la contaminación genética de entre el 3 y el $13 \%$ de las semillas locales de maíz en 15 de las 22 comunidades mexicanas de Oaxaca y Puebla. Así, una parte importante de las variedades tradicionales de maíz habrían sido contaminadas genéticamente por un tipo de maíz transgénico Bt. Según indicaron estos investigadores, lo más grave sería que este hecho podría suponer una seria amenaza para la rica diversidad genética local. Y la polémica se hizo aún más intensa cuando se recordó que el cultivo de maíz transgénico estaba prohibido en el territorio mexicano ya desde el año 1998. Se resalta además que esta zona del planeta podría constituir con mucha probabilidad el origen y el centro de la diversidad genética de todo el maíz existente en el mundo (Greenpeace, 2000). En consecuencia, como después respaldarían varias comunidades indígenas y campesinas, quedaría demostrado que con esta clara introgresión podría estar amenazándose notablemente la valiosa diversidad genética de las muchas estirpes de maíz autóctono de México (Biodiversidad, 2003).

Sin embargo, conviene percatarse de que lo que unos grupos llaman una evidente y preocupante contaminación los otros colectivos entienden sólo como una posible pre- 
sencia adventicia e intrascendente (Mendiola, 2006). Con todo, en respuesta directa a la publicación de estos resultados empíricos, algunos científicos denunciaron la existencia de posibles errores cometidos por los investigadores Chapela y Quist. Justamente, el 4 de abril de 2002, los propios editores de la revista en cuestión dijeron en un comunicado que el artículo realizado por Chapela y Quist podría contener algunos errores metodológicos y que, por tanto, este trabajo quizá nunca debiera haber sido publicado en la citada revista Nature. Así, los expertos partidarios del maíz transgénico subrayaron que lo que quedaría por esclarecer es si esta posible presencia de transgenes en las estirpes autóctonas del maíz mexicano pudiese tener unos efectos futuros realmente negativos sobre la diversidad genética del maíz y el conjunto del medio ambiente. Claro que, para estos investigadores, el posible impacto pernicioso de esta supuesta fuga no intencionada de transgenes sería siempre prácticamente nulo, inapreciable e insignificante (Muñoz Ruiz, 2002: 17-19).

Las críticas generales a este trabajo se dirigen, en consecuencia, a la metodología empleada, las conclusiones obtenidas y la corrección de la revisión efectuada por los respectivos especialistas para la revista Nature (Silva Castro, 2005: 34-38). No obstante, los investigadores californianos presentaron con posterioridad nuevos datos empíricos que darían más apoyo y solidez a la tesis central que afirma la presencia preocupante de los transgenes en el maíz mexicano autóctono (Ho y Mathews, 2002). Como ha indicado el propio Ignacio Chapela: "Creo que desde el punto de vista del control, el tema más importante para nosotros en México es la contaminación. ¿En qué grado se puede controlar un organismo transgénico que se libera en el ambiente? Nuestro trabajo del año 2000 y varios posteriores demuestran claramente que no se tiene control, que hay una contaminación muy amplia imposible de prevenir, que el viento, los pájaros y las mariposas mueven el polen de un lado a otro y que los genes se mueven con el polen" (Chapela, 2005: 30).

Así las cosas, los expertos críticos con la nueva ingeniería genética declaran que, si bien ciertas personas habrían denunciado aquí la existencia de posibles errores metodológicos, de momento ningún investigador habría refutado de un modo rigurosamente científico y técnico la posibilidad efectiva de que hayan existido los citados cruzamientos genéticos (Ho y Ching, 2004: 21-22). Se denuncia además que la industria de la nueva biotecnología impulsaría fuertes campañas de desprestigio e intimidación hacia los principales académicos disidentes que se atreverían a romper filas en la investigación sobre la viabilidad humana y ambiental de los OMG (Ho y Mathews, 2002: 168-169). Sea como fuere, y sobre todo para el público en general, la pregunta cardinal que siempre parece quedar sin una respuesta clara y contundente es si era realmente correcta o incorrecta la investigación realizada por Quist y Chapela (Chimal, 2002: 390).

Igualmente, los agentes sociales contrarios a la libre proliferación mundial de estos nuevos alimentos reconocen que el Bacillus thuringiensis (Bt) es una bacteria empleada también por muchos agricultores para combatir químicamente las plagas de algunos insectos perjudiciales (lannone, 2001). No obstante, en contraste con la aplicación ocasional de la toxina Bt en los cultivos convencionales, se critica aquí que la toxina transgé- 
nica se produciría en las plantas tratadas durante todo el tiempo en que éstas continúan desarrollándose. Así, las plantas en las que se introducen los nuevos genes para producir la toxina Bt generarían su propio insecticida de una manera excesivamente constante y progresiva. En esta línea, por tanto, se denuncia que a diferencia del uso selectivo y controlado de la toxina Bt que con anterioridad hacían muchos agricultores, con su incorporación genética a las plantas de un modo continuo y sistemático se provocaría un uso excesivo e indiscriminado que afectaría negativamente tanto a los insectos dañinos como a los insectos beneficiosos. Se precisa además que estas nuevas prácticas generarían efectos indirectos perniciosos sobre los enemigos biológicos del taladro, pues un menor número de taladros supondría también una cantidad menor de comida para sus depredadores naturales. En cualquier caso, se subraya que la toxina de los cultivos transgénicos estaría presente de forma activa en desproporción, lo cual provocaría que esta toxina pudiera repercutir adversamente en un espectro de plantas y animales mucho mayor del que estaba previsto en un principio.

En coherencia, unos estudios científicos denunciaron que el cultivo de maíz transgénico podría producir en la tierra de los agricultores una acumulación negativa y difícilmente biodegradable de la toxina Bt (Saxena et al., 1999), lo cual podría ocasionar un efecto dañino para organismos del suelo tales como las lombrices, los hongos o algunas bacterias. Se indica asimismo que esta presencia anómala favorecería, más tarde o más temprano, la aparición de resistencias en algunos de los insectos debido a la exposición continua y sistémica a la toxina Bt. Análogamente, se recuerda un hecho singular relacionado con el algodón $\mathrm{Bt}$, propiedad de la empresa transnacional Monsanto, que se habría sembrado ampliamente en el sur de EEUU. Así, según los datos que difunde esta misma empresa, este cultivo transgénico mataría oficialmente en torno al $80 \%$ de los gusanos que se comen las cápsulas del algodón Bt. Sin embargo, como por ejemplo ha señalado el profesor Fred Gould: "El 80\% de mortalidad es exactamente lo que utilizan los investigadores cuando quieren producir insectos resistentes" (Gould, 1996).

De ahí derivaría precisamente el riesgo considerable de que tanto los insecticidas químicos tradicionales como los nuevos insecticidas transgénicos pronto pudieran resultar realmente ineficaces e inservibles. Este fenómeno se produciría, al parecer, porque los insectos respectivos estarían expuestos de una forma excesivamente permanente a la toxina Bt. La constante presión ecológica padecida fomentaría así el pernicioso desarrollo de estas resistencias. Según ha señalado por ejemplo el ya citado Ignacio Chapela: "En principio el cultivo de estas plantas resulta interesante porque reduciría la cantidad de herbicida por utilizar, pero resulta que la resistencia a herbicidas en las malezas se ha incrementado muchísimo, y que, por el contrario, la sensibilidad de las plantas supuestamente resistentes ha aumentado en los campos estadounidenses desde 2001" (Chapela, 2005: 31).

En este sentido, para contrarrestar el posible surgimiento de estas adversas resistencias, las compañías vinculadas a la nueva ingeniería genética habrían aconsejado a los agricultores implicados que combinen en sus campos los nuevos cultivos con los cultivos naturales notransgénicos. La finalidad esencial de estas prácticas sería crear 
unos refugios ecológicos para los insectos en cuestión, procurando evitar así que estos se hagan resistentes muy rápidamente a los cultivos Bt (ASA, 1999). En concreto, las empresas referidas recomiendan dedicar de entre el 10 y el $20 \%$ del terreno cultivado a la construcción de estos refugios ecológicos. Así lo establece igualmente en nuestro país el respectivo plan de seguimiento impulsado y desarrollado por el Ministerio de Agricultura, Pesca y Alimentación (MAPA) (Alcalde, 2000: 49). Justamente, con el fin principal de garantizar la construcción y el mantenimiento de estos refugios ecológicos, se difunden entre los agricultores distintos folletos técnicos divulgativos a modo de guías con información sobre lo que se consideran unas buenas prácticas (APROSE, 2006; Novillo Almendros, 2006). Sin embargo, si bien las empresas del sector agroalimentario resaltan que este proceder habría tenido mucho éxito por ejemplo en algunas de las regiones norteamericanas, quedaría claro también que no todos los agricultores estarían realmente dispuestos a seguir este tipo de consejos y recomendaciones. El motivo básico de este recelo sería que estos agricultores no entenderían muy bien para qué se habrían realizado las respectivas modificaciones genéticas si, después de todo, deben tomarse tantas medidas de seguridad y prevención (Arias, 2000). De hecho, la resistencia de diversas poblaciones de insectos a las plantas transgénicas que producen la toxina $\mathrm{Bt}$ habría sido documentada también por científicos del Departamento de Entomología de la Universidad de Arizona (Tabashnik, 1994; Tabashnik, et al. 1997; Liu, et al. 1999). En esta línea crítica, se recuerda asimismo que incluso la propia agencia norteamericana ha previsto que muchos de los insectos dañinos a los que deben atacar los cultivos Bt podrían ser resistentes en gran medida a estos productos transgénicos dentro de entre tres a cinco años (EPA, 1995).

Por consiguiente, para los grupos sociales detractores de la nueva ingeniería genética, sería obvio que siempre podrían desencadenarse diversas consecuencias indeseadas e imprevistas derivadas de la creación, el cultivo, el comercio y el consumo de los distintos productos Bt. En el año 1996, por ejemplo, un grupo de agricultores norteamericanos sufrió al parecer unas pérdidas económicas considerables en relación con la cosecha del algodón Bt. El motivo principal difundido por las empresas implicadas fue que una fuerte ola de calor pudo generar de forma indirecta un apagón imprevisto del gen responsable de la producción de la toxina Bt. Este fenómeno, que los grupos sociales partidarios de los productos transgénicos considerarían sólo meramente fortuito y accidental, afectó al parecer a unas 9.000 hectáreas de cultivo de algodón que habrían sido invadidas por una plaga del insecto que las plantas transgénicas debieran haber controlado y neutralizado (Arias, 2000). También se denuncia que una consecuencia grave para el medio ambiente generada por la utilización masiva de la toxina transgénica Bt, sobre todo en los cultivos que ocupan una gran superficie del paisaje agrícola, sería que los agricultores vecinos con cultivos convencionales podrían contemplar impotentes cómo las poblaciones de los insectos resistentes colonizan y destruyen los campos donde estos agricultores usan el insecticida Bt sólo en su variante química y notransgénica. Se advierte y denuncia, en consecuencia, que este hecho podría dejar a estos agricultores en gran medida indefensos ante tales superplagas puesto que el 
plaguicida químico y notransgénico sería aquí poco eficaz y funcional, perdiendo así una herramienta muy importante para el necesario control de estas plagas de insectos perjudiciales.

\section{EL ANÁLISIS SOCIOLÓGICO DE LA CONTROVERSIA}

Hasta el momento he presentado el espacio de la argumentación y el espacio de la contra-argumentación erigidos a favor y en contra de la supuesta viabilidad humana y ambiental del denominado maíz Bt. También se ha querido, en consecuencia, tornar más transparente la compleja génesis fundacional, las diversas trayectorias espaciales y temporales y los múltiples escenarios humanos y no-humanos relacionados muy íntimamente con estos OMG (Mendiola, 2006). En lo que sigue, centrándome en el examen crítico de las heterogéneas traducciones colectivas aquí activadas y movilizadas, presentaré algunas reflexiones que pueden ayudar a entender por qué circunstancias no se ha asistido todavía a un cierre más o menos dialogado y contundente de las controversias científicas y técnicas particulares erigidas en torno a la libre circulación mundial del maíz transgénico Bt. Se trata ahora, según quedó anunciado, de realizar una conveniente labor de análisis, discusión y conclusión para la cual, por consiguiente, me serviré en gran medida de las muchas e importantes aportaciones provenientes de las nuevas orientaciones en la Sociología de la Ciencia y la Tecnología (Lamo de Espinosa, et al. 1994; Iranzo y Blanco, 1999).

Inicialmente, en relación por ejemplo con el polémico artículo del grupo de trabajo de John E. Losey, en especial en lo referente a los argumentos que se habrían movilizado para desacreditar tanto el proceso de investigación como las conclusiones derivadas de este estudio, quisiera resaltar que el paso de los laboratorios a la naturaleza exterior constituye un movimiento en gran medida forzado, violento y arriesgado. De hecho, más allá de las situaciones específicas reproducidas y reproducibles en el interior de los distintos laboratorios, merece indicarse que las predicciones respectivas sobre los posibles daños humanos y ambientales futuros asociados a los cultivos transgénicos serían siempre tan necesarias socialmente como artificiales y vulnerables desde el punto de vista de los grupos sociales partidarios o detractores de los OMG. En este sentido, en contra pues de la habitual concepción de la lógica de la investigación más idealista y metafísica, cabría subrayar de momento que en las actuales prácticas empíricas particulares difícilmente puede demostrarse plenamente la posible veracidad o falsedad de los enunciados más abstractos, generales y universales (Popper, 1962). Justamente, uno de los motivos esenciales de esta gran dificultad se refiere por ejemplo a que estas demostraciones científicas tan exigentes y pretenciosas dependerían, para empezar, de las condiciones puntuales que son reproducidas y reproducibles en los laboratorios respectivos de un modo siempre abierto, contingente y problemático (Latour y Woolgar, 1995).

Asimismo, parece casi obvio que el periodo de tiempo concreto de exposición a los productos que son evaluados y la cantidad específica de los animales que son utilizados 
en muchos de los experimentos podría limitar de manera notable tanto la solvencia metodológica de los estudios realizados como la significatividad científica de las conclusiones respectivas (Domingo Roig y Gómez Arnáiz, 2000: 257). Claro que la tarea central que podemos realizar como analistas sociales de esta polémica específica no consiste en dilucidar por ejemplo cuántos días de experimentación son realmente necesarios para determinar la llamada validez ecológica de los distintos experimentos, sean estos más o menos de 10, 30 o 100. En cambio, como intérpretes de este enfrentamiento cognitivo, discursivo y práctico, resulta primordial observar que, cualesquiera que sean los días 0 el número de animales finalmente utilizados en los procesos de evaluación de la seguridad humana y ambiental, para unos expertos estos días y cantidades casi siempre serán más que suficientes, mientras que para otros especialistas que en efecto pueden ser tan solventes y rigurosos como los anteriores estos mismos días y cantidades casi siempre serán muy inferiores a los realmente necesarios o convenientes (López Cerezo y Luján López, 2000).

De forma que si esta discusión particular todavía no puede ser clausurada en unos términos exclusivamente racionales y empíricos ello también podría deberse al ya referido problema de la validez ecológica de los distintos pronunciamientos teóricos y empíricos. Justamente, esta misma cuestión sería ciertamente importante, compleja y arriesgada en aquellos objetos de experimentación vivos que son muy sensibles a las condiciones externas o ambientales. En concreto, hacer frente al problema de la validez ecológica de los distintos experimentos supone por ejemplo cuestionarse hasta qué punto en el interior de los laboratorios pueden imitarse y reproducirse, de un modo siempre precario y cuestionable, las complejas condiciones sociales y ambientales existentes en el mundo exterior (Collins y Pinch, 1996). Lo que ocurriría es pues que difícilmente pueden predecirse de un modo totalmente preciso, exacto y completo las consecuencias reales derivadas de la entrada en escena de determinados productos y prácticas en ese mundo exterior ubicado más allá de las paredes de los lugares de experimentación. Se entiende así la presencia en estos enfrentamientos tecnocientíficos y socioculturales de una enorme flexibilidad en los relatos y las interpretaciones. Con lo cual, las posibles consecuencias a medio y largo plazo fruto de la introducción de un producto transgénico como el maíz Bt, del interior de los laboratorios a la naturaleza exterior, siempre resultarían difícilmente previsibles y controlables. En consecuencia, parece razonable reconocer aquí que la capacidad efectiva de predicción y dominación de la poderosa tecnociencia actual siempre presentaría también inevitables fisuras, sombras o limitaciones (Beriain, 1996; Wynne, 1997).

Existirían, por tanto, muchas opiniones difundidas pero muy pocos datos concluyentes disponibles sobre el conocimiento de las posibles consecuencias adversas generadas por la libre proliferación mundial de los OMG (Domingo Roig, 2000). Se presenta, en todo caso, un problema cognitivo inicial sobre la predicción de los posibles efectos futuros pero también un problema normativo ulterior relativo a las variadas estrategias de gestión de los distintos riesgos y conflictos asociados (López Cerezo y Luján López, 2000). En este sentido, por tanto, como bien han señalado por ejemplo los científicos Wolfenbarger y Phifer en la prestigiosa revista Science: "Nuestra capacidad para 
predecir los impactos ecológicos de las especies introducidas, incluidos los OMG, es imprecisa, y la información usada para evaluar los potenciales impactos ecológicos tiene límites. Nuestra incapacidad para predecir apropiadamente las consecuencias ecológicas, especialmente a largo plazo, [...] aumenta la incertidumbre asociada a la gestión del riesgo y puede requerir modificaciones en las estrategias de gestión de los riesgos" (Wolfenbarger y Phifer, 2000).

Así las cosas, la normativa europea estableció en su día que la licencia concedida al maíz Bt podría ser retirada sólo si se aportan determinados argumentos racionales y pruebas empíricas que expliciten la existencia de una duda científica razonable en relación con la posible peligrosidad de este OMG. Y sabemos bien que el principio de precaución conduce a entender que un producto transgénico concreto no deberá permanecer en el mercado si se presenta una duda científica razonable acerca de su posible toxicidad para la salud humana o el medio ambiente (Riechmann y Tickner, 2002). Sin embargo, para los grupos sociales detractores de estos nuevos productos, ya existiría un conjunto de argumentos racionales y de pruebas empíricas lo suficientemente sólido y preocupante como para determinar la existencia de una duda científica realmente razonable y significativa. Como ha expresado por ejemplo Zac Goldsmith, quien fuera director de la revista The Ecologist: "Pero incluso cuando la ciencia plantea serias dudas sobre la seguridad de experimentos concretos, se la ignora por completo a menos que sus hallazgos coincidan con los intereses de la industria. Por ejemplo, la investigación suiza sobre una variedad de maíz modificado genéticamente, diseñada por Novartis [hoy llamada Syngenta] como veneno para la larva del perforador del maíz, ha demostrado que [este producto] puede matar tanto a insectos beneficiosos como a nocivos, lo que altera toda la cadena alimentaria. Y aun así, la Unión Europea ha declarado que la licencia concedida al maíz modificado genéticamente sólo podrá retirarse si se aportan nuevas pruebas científicas que cuestionen su seguridad. Pero estas pruebas [...] son precisamente las que los científicos suizos han aportado [Hilbeck, et al. 1998]. Quizá para la UE la investigación sólo pueda clasificarse como científica si sirve para promover los intereses de la industria biotecnológica" (Goldsmith, 1998: 63-64).

Claro que, sea como fuere, la supuesta situación de incertidumbre científica haría que resulte muy complejo y esté sujeto a múltiples discusiones consensuar de una forma dialogada y contundente hasta qué punto la totalidad de las críticas científicas presentadas por los grupos sociales detractores de estos nuevos productos merece ser considerada acorde con el comentado principio de precaución como una duda científica realmente razonable y significativa (Sentís Castaño, 2002; Ramos Torre, 2002). Más exactamente, debe señalarse que la propia situación de incertidumbre científica es tan intensa, ambigua y determinante que, si por un lado es negada por los argumentos que muestran la real y reveladora dominación relativa del mundo natural, por otro lado es afirmada por los argumentos que documentan la resistencia que siempre presenta esta naturaleza a ser completamente sometida y domesticada. El lenguaje social más entusiasta e innovador que ensalza el espacio de la razón, la seguridad, la certidumbre y el conocimiento sería cuestionado y contrarrestado así por ese otro lenguaje social 
más prudente y desconfiado que subraya a su vez el espacio del riesgo, la ignorancia, la incertidumbre y la indeterminación. En cualquier caso, la descripción y el examen detallado de esta controversia específica permiten concluir, cuando menos desde un punto de vista sociológico, que la discusión particular sobre hasta qué punto los argumentos expuestos y las pruebas empíricas esgrimidas en contra de la viabilidad humana y ambiental de este maíz transgénico representan una duda científica suficientemente significativa y preocupante no parece ser un fácil problema a dilucidar en términos, en principio, exclusivamente racionales y empíricos. Se impone por fuerza, entonces, que semejantes circunstancias estructurales deberían conducir a los estudios sociales de la ciencia y la tecnología no tanto a concluir radicalmente que la racionalidad científica y la práctica experimental son procesos humanos en gran medida ficticios, ilusorios e imposibles sino más bien a matizar con precisión que estos mismos procesos efectivos estarían siempre generados y limitados por determinados antecedentes y consecuentes de naturaleza inequívocamente económica, política y sociocultural. Y así, movilizando por ende una muy necesaria reflexividad sociológica, parece razonable explicitar a modo de conclusión que los nuevos productos transgénicos no deberían concebirse fuera del intrincado mundo natural que en gran medida los reinventa, los ordena y los restringe como tampoco los científicos y técnicos expertos propios de las actuales sociedades occidentales deberían entenderse al margen por completo del también muy conflictivo y enmarañado mundo social que innegablemente los posibilita, los organiza y los condiciona.

\section{REFERENCIAS BIBLIOGRÁFICAS}

Alcalde, E. 1997. "Maíz autoprotegido contra el taladro". Vida Rural. 50: 36-37.

Alcalde, E. 2000. "Compa CB. Un maíz mejorado genéticamente resistente a plagas". Vida Rural. 7: 48-49.

APROSE. 2006. Guía de buenas prácticas para el cultivo de maíz Bt. Madrid: Asociación Profesional de Empresas Productoras de Semillas Selectas.

Arias, M. 2000. Las plagas adquieren resistencia. Barcelona: Asociación Vida Sana.

ASA. 1999. Utilización de refugios en maíces Bt. Buenos Aires: Programa de Productividad Sustentable. Asociación de Semilleros Argentinos (ASA).

Beltrán Villalva, M. 2000. Perspectivas sociales y conocimiento. Barcelona: Anthropos.

Beriain, J. 1996. comp. Las consecuencias perversas de la modernidad. Barcelona: Anthropos.

Birch, A.N.E., I.E. Geoghegan, M. E.N. Majerus, C. Hackett y J. Allen. 1996-1997. "Interactions Between Plant Resistance Genes, Pest Aphid Populations and Beneficial Aphid Predators". Scottish Crop Research Institute. Dundee. Annual Report. 1996-1997: 68-72. 
Borlaug, N. E. 1999. "Los ecologistas extremistas impiden erradicar el hambre". El País. 28 de octubre de 1999.

Bourdieu, P. 2003. El oficio de científico. Ciencia de la ciencia y reflexividad. Barcelona: Anagrama.

Brake, J. y D. Vlachos. 1998. "Evaluation of Transgenic Event 176 "Bt" Corn in Broiler Chickens". Poultry Science. 77: 648-653.

Collins, H. M. y T.J. Pinch. 1996. El gólem. Lo que todos deberíamos saber acerca de la ciencia. Barcelona: Crítica.

Chapela, I. 2005. “¿Quién necesita transgénicos?”. En Transgénicos, ¿quién los necesita?, A. Batra et al. comp., pp. 27-37. México: Grupo Parlamentario del Partido de la Revolución Democrática.

Chimal, C. 2002. "El dilema de los organismos transgénicos". Avance y Perspectiva. 21: 389-401.

Dalton, R. 2001. "Transgenic Corn found Growing in Mexico". Nature. 413: 337.

Domingo Roig, J.L. 2000. "Health Risks of GM Foods. Many Opinions but Few Data". Science. 288: 1748-1749.

Domingo Roig, J. L. y M. Gómez Arnáiz. 2000. "Riesgos sobre la salud de los alimentos modificados genéticamente. Una revisión bibliográfica”. Revista Española de Salud Pública. 74: 255-261.

EPA. 1995. Bacillus Thuringiensis Cry 1A(b) Delta-Endotoxin and the Genetic Material Necessary for its Production in Corn. Event Bt-176 for Ciba-Novartis and Mycogen. USA: Pesticide Fact Sheet. Environmental Protection Agency (EPA-OPPTS).

EPA. 2000. Informe sobre las mariposas Monarca y las plantas transgénicas Bt. USA: Scientific Advisory Panel. Environmental Protection Agency (SAP-EPA).

Goldsmith, Z. 1998. “¿Ecoguerrilleros o vándalos? ¿Quiénes son los auténticos terroristas?”. The Ecologist. 28: 62-65.

Gould, F. 1996. "Bt Cotton Infestations Renew Resistance Concerns". Nature Biotechnology. 14: 1070.

Greenpeace. 2000. Centros de diversidad. La riqueza biológica de los cultivos tradicionales, herencia mundial amenazada por la contaminación genética. México: Greenpeace de México.

Hanson-Jesse, L. C. y J.J. Obrycki. 2000. "Field Deposition of Bt Transgenic Corn Pollen: Letal Effects on the Monarch Butterfly". Oecologia. 125: 241-248.

Hilbeck, A., M. Baumgartnew, P.M. Fried y F. Bigler. 1998. "Toxicity of Bacillus Thuringiensis Cry1Ab Toxin to the Predator Chrysoperla Carnea (Neuroptera. Chrisopidae)". Environmental Entomology. 27: $1255-1263$.

Ho, M-W y L.L. Ching. 2004. En defensa de un mundo sustentable sin transgénicos. Londres: Institute of Science in Society. Third World Network.

Ho, M-W. y J. Mathews. 2002. "Declaración conjunta internacional sobre el escándalo de la contaminación con maíz transgénico en México". Ecología Política. 23: 166-170. 
lannone, N. 2001. Control químico de Diatraea. Tecnología que apunta a la alta producción. Buenos Aires: Pergamino. Instituto Nacional de Tecnología Agropecuaria (INTA)

Iranzo, J. M. y J.R. Blanco. 1999. Sociología del conocimiento científico. Madrid: CIS y UPNA.

James, C. 2005. Situación global de los cultivos transgénicos comercializados: 2005. Briefs 34. Ithaca. Nueva York: International Service for the Acquisition of Agri-Biotech Applications (ISAAA).

Lamo de Espinosa, E., J.M. González García y C. Torres Albero. 1994. La sociología del conocimiento y de la ciencia. Madrid: Alianza.

Latour, B. y S. Woolgar. 1995. La vida en el laboratorio. La construcción de los hechos científicos. Madrid: Alianza.

Liu, Y-B., B.E. Tabashnik, T.J. Denneby, A.L. Patin y A.C. Barlett. 1999. "Development Time and Resistance to Bt Crops". Nature. 400: 519.

López Cerezo, J. A. y J.L. Luján López. 2000. Ciencia y política del riesgo. Madrid: Alianza.

Losey, J. E., L.S. Rayor y M.E. Carter. 1999. "Transgenic Pollen Harms Monarch Larvae”. Nature. 399: 214.

Mármol, E. 2002. "Impacto ocasionado por el uso de maíz en las fincas de España". Vida Rural. 9: $32-34$.

Martínez, G. 1997. "Panorámica general del cultivo del maíz". Vida Rural. 53: 49-51.

Mendiola, I. 2006. El jardín biotecnológico. Tecnociencia, transgénicos y biopolítica. Madrid: La Catarata.

Muñoz Ruiz, E. 2002. "Los medios de comunicación y los alimentos modificados genéticamente. Conflicto entre conocimiento e información". IESA-CSIC. Documento de Trabajo 02-11.

Novillo Almendros, C. 2006. "Buenas prácticas con el maíz Bt para asegurar sus beneficios en el futuro". Agricultura: Revista Agropecuaria. 75: 222-223.

Obrycki, J. J., J.E. Losey, O.R. Taylor y L.C. Hanson-Jesse. 2001. "Transgenic Insecticidal Corn: Beyond Insecticidal Toxicity to Ecological Complexity". BioScience. 51: 353-361.

Pacheco-Vega, H. R. y O. Vega-López. 2001. "La controversia de la mariposa Monarca. Un análisis a la luz de las teorías sociales del riesgo". Convergencia. 26: 145-169.

Peinado, D. 1999. "Transgénicos. ¿Alimentos que matan o remedio contra el hambre?". El Semanal. pp. 34-46.

Popper, K. R. 1962. La lógica de la investigación científica. Madrid: Tecnos.

Quist, D. y I. Chapela 2001. "Transgenic DNA Introgressed into Traditional Maize Landraces in Oaxaca, Mexico". Nature. 414: 541-543. 
Ramos Torre, R. 2002. "El retorno de Casandra. Modernización ecológica, precaución e incertidumbre". En ¿Más allá de la modernidad?, García Blanco, J. Mª. y P. Navarro Sustaeta, comps., pp. 403-455. Madrid: CIS.

Red en Defensa del Maíz. 2003. La contaminación transgénica del maíz campesino en México. México, CECCAM, CENAMI, Grupo ETC, CASIFOP, UNOSJO y AJAGI.

Riechmann, J. y J. Tickner. 2002. eds., El principio de precaución en medio ambiente y salud pública. De las definiciones a la práctica. Barcelona: Icaria.

Sampedro, J. 1999. "Los transgénicos, a la luz de los argumentos". El País. 7 de diciembre de 1999.

Saxena, D., Flores, S. y Stotzky, G. 1999. "Transgenic Plants: Insecticidal Toxin in Roots Exudates from Bt Corn". Nature. 402: 430-431.

Sears, M. K., et al. 2001. "Impact of Bt Corn Pollen on Monarch Butterfly Populations. A Risk Assessment". Proceedings of the National Academy of Sciences. 98: 11.937-11.942.

Sentís Castaño, C. 2002. "Ingeniería genética. Insuficiencias teóricas y la aplicación del principio de precaución". Política y Sociedad. 39: 627-639.

Silva Castro, C. A. 2005. Maíz genéticamente modificado. Bogotá. Colombia: AGRO-BIO.

Spendeler, L. y J.F. Carrasco. 2003. Al grano. Impacto del maíz transgénico en España. Amigos de la Tierra y Greenpeace. Alcobendas: Industrias Gráficas EPES.

Seeds, S. 1997. El maíz sigue siendo maíz. ¿Por qué necesitamos la tecnología genética? Basilea: Syngenta Seeds.

Tabashnik, B.E. 1994. "Evolution of Resistance to Bacillus Thuringiensis". Annual Review of Entomology. 39: $47-49$.

Tabashnik, B.E., et al. 1997. "One Gene in Diamondback Moth Confers Resistance to Four Bt Toxins". Proceedings of the National Academy of Sciences. (USA). 94: 1640-1644.

Wolfenbarger, L. L. y P.R. Phifer. 2000. "The Ecological Risks and Benefits of Genetically Engineered Plants". Science. 290: 2088-2092.

Wynne, B. 1997. "Incertidumbre y aprendizaje ambiental. Reconcebir la ciencia y la política en un paradigma preventivo". En Ciencia, tecnología y sociedad. Lecturas seleccionadas. González García, M. I., J.A. López Cerezo y J.L. Luján López. 1997. pp. 161-183. Barcelona: Ariel. 
JÓSEAN LARRIÓN CARTUJO (Pamplona, 1976) es Licenciado en Sociología por la Universidad Pública de Navarra (1996-2000). Suficiencia Investigadora y Diploma de Estudios Avanzados por la Universidad Complutense de Madrid (2000-2002). Doctor en Sociología por la Universidad Complutense de Madrid (2005). Premio Extraordinario de Doctorado por la Facultad de Ciencias Políticas y Sociología de la Universidad Complutense de Madrid (2004-2005). Profesor Asociado Doctor en el Departamento de Sociología de la Facultad de Ciencias Humanas y Sociales de la Universidad Pública de Navarra (2008-2010).

\section{RECIBIDO: 26/02/08}

ACEPTADO: 21/01/09

Publicado on-line: 30 de noviembre de 2009 